\title{
The Importance of Interfacial Tension in Emulsification: Connecting Scaling Relations Used in Large Scale Preparation with Microfluidic Measurement Methods
}

\author{
Karin Schroën ${ }^{1,2, *(\mathbb{D})}$, Jolet de Ruiter ${ }^{1}(\mathbb{D})$ and Claire Berton-Carabin ${ }^{1,3}$ \\ 1 Food Process Engineering Group, Wageningen University, Bornse Weilanden 9, \\ 6708 WG Wageningen, The Netherlands; jolet.deruiter@wur.nl (J.d.R.); \\ claire.berton-carabin@inrae.fr (C.B.-C.) \\ 2 Membrane Processes for Food Group, University of Twente, Drienerlolaan 5, \\ 7522 NB Enschede, The Netherlands \\ 3 INRAE, UR BIA (Food and the Environment, Unit Biopolymers, National Research Institute for Agriculture, \\ Interactions, Assemblies), F-44316 Nantes, France \\ * Correspondence: karin.schroen@wur.nl; Tel.: +31-317-483396
}

Received: 17 August 2020; Accepted: 23 November 2020; Published: 7 December 2020

check for updates

\begin{abstract}
This paper starts with short descriptions of emulsion preparation methods used at large and smaller scales. We give scaling relations as they are generally used, and focus on the central role that interfacial tension plays in these relations. The actual values of the interfacial tension are far from certain given the dynamic behavior of surface-active components, and the lack of measurement methods that can be applied to conditions as they occur during large-scale preparation. Microfluidic techniques are expected to be very instrumental in closing this gap. Reduction of interfacial tension resulting from emulsifier adsorption at the oil-water interface is a complex process that consists of various steps. We discuss them here, and present methods used to probe them. Specifically, methods based on microfluidic tools are of great interest to study short droplet formation times, and also coalescence behavior of droplets. We present the newest insights in this field, which are expected to bring interfacial tension observations to a level that is of direct relevance for the large-scale preparation of emulsions, and that of other multi-phase products.
\end{abstract}

Keywords: emulsification; emulsions; interfacial tension; microfluidic devices; droplet volume tensiometry; coalescence

\section{Introduction}

Emulsions, which are dispersions of one liquid phase in another, may become physically unstable due to various causes such as creaming, sedimentation, flocculation, phase inversion, and coalescence, and these mechanisms are dependent on, amongst others, droplet size, size distribution, amount and type of emulsifier, mutual solubility of the two phases, and agitation [1]. When focussing on droplet formation, as is done mostly in this paper, it is clear that making small droplets results in high surface free energy of the emulsion $\Delta G(\mathrm{~J}$; Equation (1)) through an increase in surface area, which is energetically unfavorable, and a driver for droplet coalescence [2]. This equation also shows that emulsifier adsorption, which results in a reduction of interfacial tension, lowers the interface free energy, and thus favours emulsification and emulsion stability.

$$
\Delta G=\sigma \Delta A
$$


In which $\sigma(\mathrm{N} / \mathrm{m})$ denotes interfacial tension, and $\Delta A\left(\mathrm{~m}^{2}\right)$ the total interfacial area. $\Delta G$ is generally positive, meaning that emulsions tend to physically destabilise in time and go back to their unmixed state [3,4].

Equation (1) is a basic principle of thermodynamics, that underlies many emulsion products that are successfully produced at large scale for a wide range of applications (food, pharma, paints, personal care, etc.). In order to prevent destabilisation, emulsifiers (or particles, in case of so-called Pickering emulsions), need to be present in the interface, where they can slow down drainage of the films in between droplets [5], through van der Waals, steric and electrostatic interactions between the droplet surfaces [6]. Further, emulsifiers may increase surface elasticity, which hampers droplet coalescence [2]. Besides this, the flow conditions in the continuous phase determine the droplet contact time, and this co-decides whether droplet (re-)coalescence will take place or not [7]. All these aspects need to come together in emulsion production, which is far from trivial, and often based on trial-and-error emulsion formulation and process optimisation.

The most important equipment used for emulsion production at large scale are high-pressure homogenisers, rotor-stator homogenisers, colloid mills, stirred tanks, and ultrasound devices, and for specialty products also membrane emulsification and microfluidic emulsification have been applied. All these methods have their specific applications in regard to viscosity, droplet size, and other pros and cons that are extensively described by Rayner [8] as summarized in Table 1.

From this table, it is clear that most methods are suitable for low to medium viscosity emulsions, the only exception being the colloid mill that also can be used for highly viscous emulsions. The droplet size is also quite different between equipment, with smaller to medium sizes found for high energy density methods such as high-pressure homogenisation. Emulsification is still a growing field, with many methods that are able to produce large amounts of products. Although not yet available at large scale, membrane and microchannel emulsification stand out because of their exceptionally high energy-efficiency.

In the next section, first, classic emulsification techniques are discussed, shortly after which droplet formation mechanisms are summarized, including scaling relations. From these it is clear that interfacial tension plays a pivotal role. Next, methods for interfacial tension measurement are presented, that in general are not able to be measured within short time intervals-unlike novel methods such as microfluidics. Additionally, we highlight how these devices can be used to measure interfacial tension at very short droplet formation times. We wrap up with future perspectives for these devices. 
Table 1. Some features of common methods and machines to produce emulsions.

\begin{tabular}{|c|c|c|c|c|c|c|c|}
\hline Homogenizer Types & $\begin{array}{c}\text { Flow } \\
\text { Regime }\end{array}$ & $\begin{array}{l}\text { (Un)-Bounded } \\
\text { Flow }\end{array}$ & $\begin{array}{l}\text { Energy Density } \\
\left(\mathrm{Jm}^{-3}\right)\end{array}$ & $\begin{array}{l}\text { Relative Energy } \\
\text { Efficiency }\end{array}$ & $\begin{array}{c}\text { Droplet sizes } \\
\text { Achieved }\end{array}$ & Viscosity & Typical Volumes \\
\hline Stirred tanks & TI, TV, LV & $\mathrm{U}$ & Low-High & Low & $\begin{array}{c}2 \mu \mathrm{m} \\
\text { and larger }\end{array}$ & low to medium & $\begin{array}{l}\text { batches up to } \\
\text { several } \mathrm{m}^{3}\end{array}$ \\
\hline Colloid mill & LV (TV) & B & $\begin{array}{l}\text { Low-High } \\
10^{3} \text { to } 10^{8}\end{array}$ & Inter-mediate & 1 to $5 \mu \mathrm{m}$ & medium to high & 4 to $20,000 \mathrm{lh}^{-1}$ \\
\hline Tooth disc disperser (e.g., Ultraturrax) & TV & B & Low-High $10^{3}$ to $10^{8}$ & Inter-mediate & $1-10 \mu \mathrm{m}$ & low to medium & $\begin{array}{l}\text { batches } \mathrm{cm}^{3} \\
\text { up to several m}\end{array}$ \\
\hline High-pressure homogenizer & $\begin{array}{l}\text { TI, TV, } \\
(\mathrm{CI}), \mathrm{LV}\end{array}$ & $\mathrm{U}$ & $\begin{array}{c}\text { Medium-High } \\
10^{6} \text { to } 10^{8}\end{array}$ & High & $0.1 \mu \mathrm{m}$ & low to medium & 100 to $20,000 \mathrm{lh}^{-1}$ \\
\hline Ultrasonic probe & $\mathrm{CI}$ & $\mathrm{U}$ & $\begin{array}{c}\text { Medium-High } \\
10^{6} \text { to } 10^{8}\end{array}$ & Low & $0.1 \mu \mathrm{m}$ & low to medium & batches $<100 \mathrm{~cm}^{3}$ \\
\hline Ultrasonic jet & $\mathrm{CI}$ & $\mathrm{U}$ & $\begin{array}{c}\text { Medium-High } \\
10^{6} \text { to } 10^{8}\end{array}$ & High & $1 \mu \mathrm{m}$ & low to medium & 1 to $500,000 \mathrm{lh}^{-1}$ \\
\hline Micro-fluidization & $\mathrm{TI}, \mathrm{TV}$ & $\mathrm{B} / \mathrm{U}$ & $\begin{array}{c}\text { Medium-High } \\
10^{6} \text { to } 10^{8}\end{array}$ & High & $<0.1 \mu \mathrm{m}$ & low to medium & up to $12,000 \mathrm{lh}^{-1}$ \\
\hline Membrane and Micro-channel & $\begin{array}{l}\text { Injection } \\
\text { STB }\end{array}$ & B & Low $10^{3}$ & $\begin{array}{c}\text { Exceptionally } \\
\text { high }\end{array}$ & $\begin{array}{c}0.3 \mu \mathrm{m} \text {-often } \\
\text { larger }\end{array}$ & low to medium & $\begin{array}{l}\text { batch or semi- } \\
\text { continuous } 10^{\prime} \mathrm{s} \mathrm{lh}^{-1}\end{array}$ \\
\hline
\end{tabular}




\section{Emulsification Devices}

First, we briefly discuss the high-pressure homogenizer, rotor-stator systems, and ultrasound systems that are used to make emulsions at large scale (Figure 1), and shortly touch upon membrane emulsification. For these techniques, a coarse emulsion that is not stable due to the large size of the droplets (Equation (1)) is used as a starting point. The emulsification device reduces the droplet size, and multiple passages are often needed.

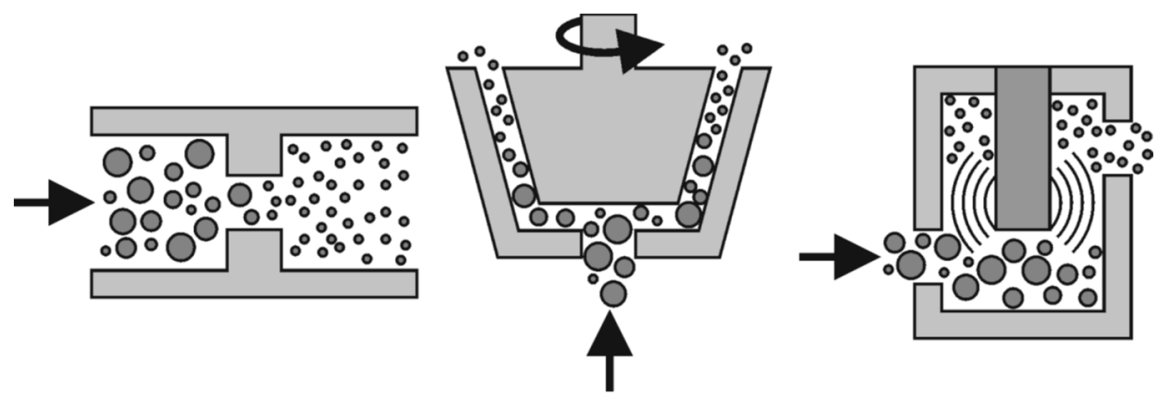

Figure 1. Schematic representation of classic emulsification methods. Left: high-pressure homogenizer, middle: rotor-stator system. Right: ultrasound [9] (reproduced with permission from the author).

During high-pressure homogenization (Figure 1, left image), a pre-emulsion is pushed through a tiny orifice, which creates local high shear. As a consequence, turbulence occurs, and possibly cavitation, which all lead to droplet break-up (Figure 2). The pressure range at which high-pressure homogenizers usually operate is $10-50 \mathrm{MPa}$, leading to very intense flow fields that lead to submicron droplets.

Lab-scale homogenizers generally still operate in the laminar flow regime [10], but industrial-scale systems operate in the turbulent regime, and as a consequence, translation of results obtained in the lab to those obtained in large-scale emulsification is rather difficult, if not impossible [11]. A lot of work has been carried out in the KIT group of Schuchmann, and the ETH Zurich group of Windhab. These groups have, amongst others, investigated the flow fields in various geometries (Figure 2) [12]. This is very challenging, given the extreme conditions that are used: small droplet sizes and very fast processes occurring. This inevitably leads to big challenges in modeling, for which the Navier-Stokes equations would need to be solved at a local level which implies nanometer scale, and also at sub-milli second time-scales [13]. Furthermore, droplets influence both each other and the local flow field in their surroundings, and this adds greatly to the numerical challenges.

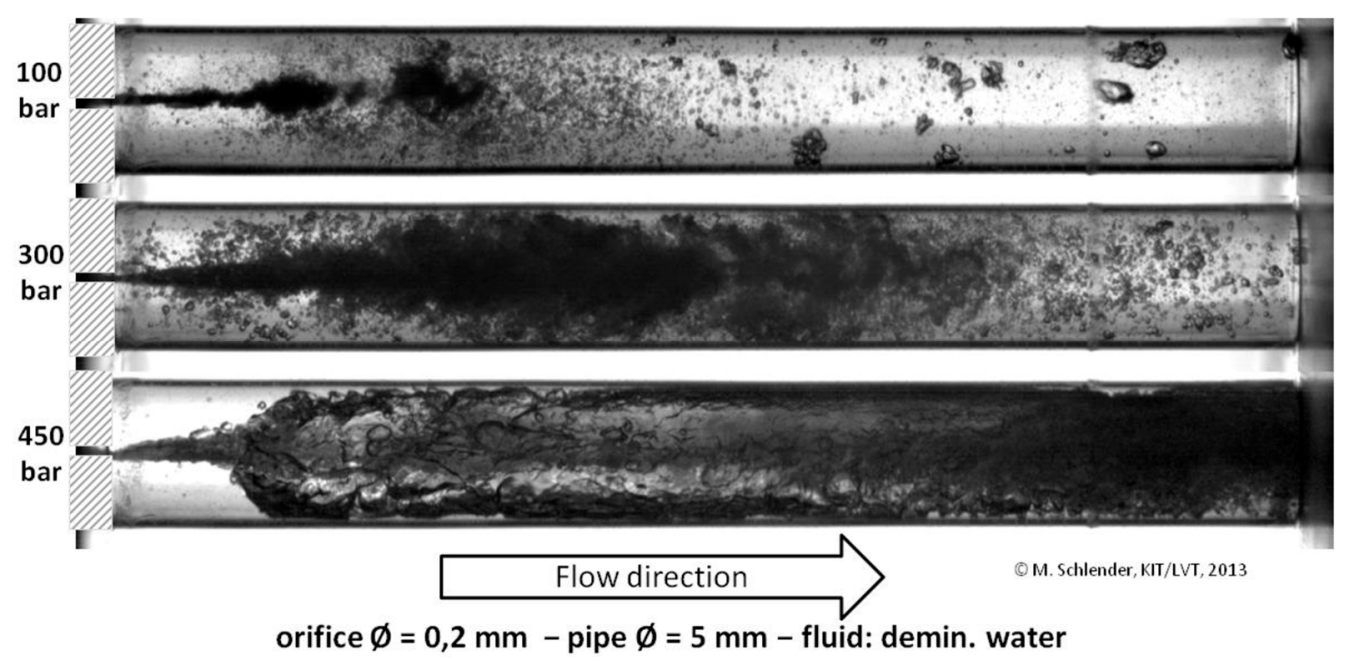

Figure 2. Cavitating fluid leaving a homogenization orifice at different homogenization pressures. Recorded at 50,000 fps and shutter speed $\sim 5$ s. Reprinted with permission from Springer from [14]. 
Urban and co-workers [15] published an extensive review on rotor-stators (see Figure 3 for images), of which many variations exist. The distance between the rotor and stator is small to generate high shear rates. Depending on the emulsion viscosity, the flow may be laminar (viscous) or turbulent.

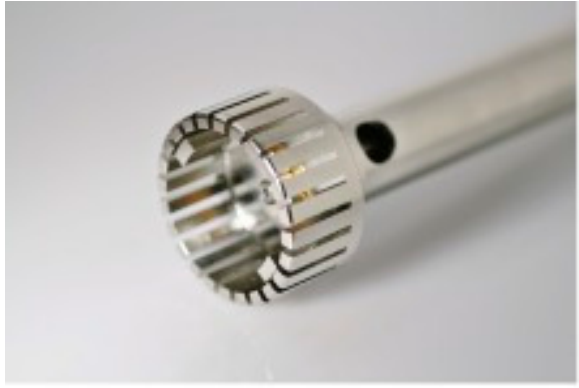

(A)

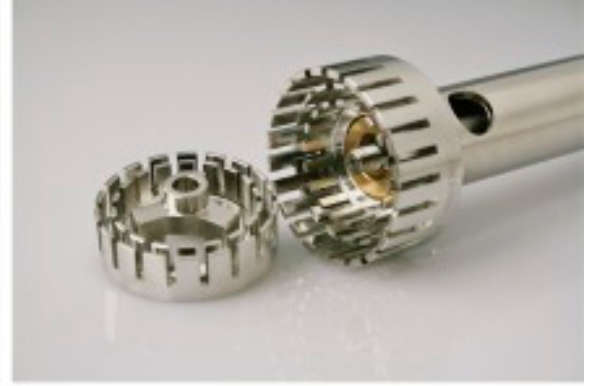

(B)

Figure 3. High shear rotor-stator system (A), and its parts (B) [16].

Ultrasound is generated by an actuator, which results in pressure fluctuations (standing waves) that induce the formation of small bubbles that implode and cause intense local turbulence (Figure 1). Canselier et al. [17] reviewed this technology, and the interested reader is referred to this paper. The effect of ultrasound is local [18], so the premix emulsion needs to be in close proximity of the actuator where the field is strongest, and the effect dies away rapidly with distance. Chemical changes can be a result of ultrasound treatment; in particular, radical species may be generated, which can cause unsaturated lipids to oxidize. In limited cases ultrasound is used to generate very small stable droplets in specialty products [19].

Although not as extensively as the previously mentioned methods, membrane emulsification has been applied in, e.g., pharma and food. In general, two distinct forms can be distinguished based on the starting liquids that are either two liquids (cross-flow or direct emulsification), or a coarse emulsion (pre-mix emulsification), as schematically illustrated in Figure 4.
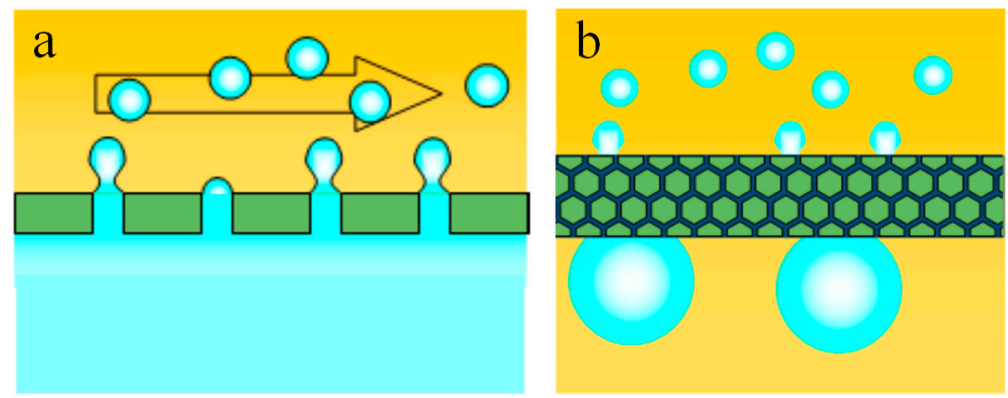

Figure 4. Schematic representations of (a) cross-flow membrane emulsification, in which the cross-flowing continuous phase shears-off the droplets that are formed. (b) Pre-mix emulsification, in which the droplets of a coarse emulsion (bottom) are broken up into smaller ones (top) upon passage through a membrane; image courtesy of Remko Boom (Wageningen University).

Cross-flow emulsification implies pushing the to-be-dispersed phase through a membrane (left image in Figure 4). Shear is used to detach the droplets, which can be delivered by a cross-flowing continuous phase [20], membrane rotation [21,22], or vibration [20]. Compared to a high-pressure homogenizer or a colloid mill, the applied shear is considerably lower in cross-flow membrane emulsification [23] (Table 1), which improves energy efficiency (energy usage is typically $5 \%$ of that of a high-pressure homogenizer) and decreases coalescence [24]. The process is known for its monodisperse emulsions, and is suitable for the use of heat- or shear-sensitive ingredients [25]. 
Pre-mix membrane emulsification, starts with a coarse emulsion that is pushed through a membrane or sieve to break it up into smaller droplets (Figure 4, right panel: [26]). Compared to cross-flow membrane emulsification, the fluxes can be much higher, and also small droplets can be generated, but they are less uniform. Because the emulsion as a whole is pushed through the membrane, it is also more prone to fouling and blocking $[27,28]$. As an alternative, metal sieves with straight-through pores [29-31], and that can be applied in conjunction with packed beds of glass beads were suggested [32]. These systems are easier to clean and combine that with high fluxes [33]. They have even been successfully applied for foams [34], double emulsion production [35] including food grade systems [36,37], and encapsulation purposes [38] including vitamins [39] and food flavors [40].

\section{Droplet Formation Mechanisms}

Emulsification devices may work under rather different conditions (e.g., laminar versus turbulent), leading to various droplet formation mechanisms occurring. Here we first discuss these mechanisms, also to link them with the dimensionless numbers that will be used later in Table 2.

When a discrete droplet is in a continuous liquid that flows around it, it experiences a shear force that may break the droplet, that is, if it exceeds the interfacial tension force that tries to keep the droplet intact. This balance is often described by the Weber number (We) which represents the ratio of the external disruptive stress and the internal coherent stress. The Weber number indicates whether a droplet can be disrupted or not. To determine the Weber number, we need to calculate the two competing stresses on the droplet interface. The coherent stress due to interfacial tension is determined by the Laplace pressure $\left(\Delta P_{\text {Laplace, }}, \mathrm{Pa}\right)$, defined as:

$$
\Delta P_{\text {Laplace }}=\frac{2 \sigma}{R_{d}}
$$

For a spherical droplet, with $R_{d}$ the droplet radius, and $\sigma$ the interfacial tension $(\mathrm{N} / \mathrm{m})$. The external disruptive stress depends on the flow conditions as discussed in the next section.

\subsection{Laminar Plain Shear Flow}

When a droplet is subjected to simple laminar flow, this will lead to droplet rotation or extension, as indicated in Figure 5a; both effect leading to the parent droplet breaking up into smaller droplets.
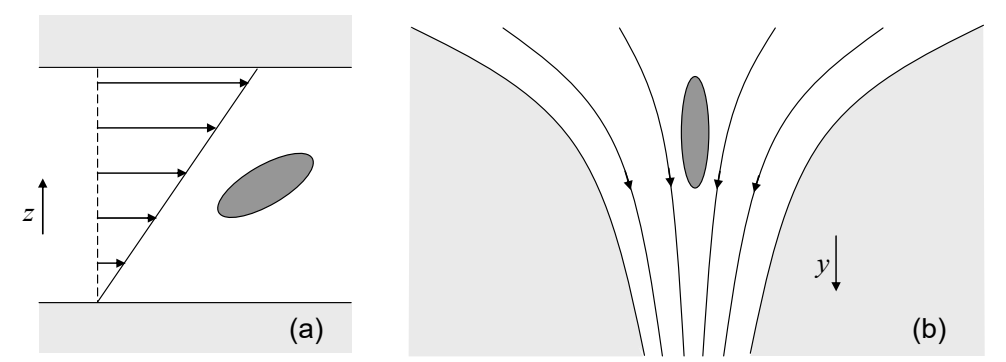

Figure 5. Simple shear flow (a) and extensional flow (b); image reproduced with permission from Walstra [41].

The disruptive stress is equal to:

$$
\tau_{\text {ext }}=\eta_{c} \dot{\gamma}
$$

in which $\eta_{c}$ is the continuous phase viscosity (Pa s), and $\dot{\gamma}$ is the applied shear rate (1/s). For simple shear flow, the velocity gradient $\mathrm{d} v_{x} / \mathrm{d} z$ determines the shear rate. As indicated in Figure $5 \mathrm{a}$, the shear rate related to the change in parallel flow velocity in perpendicular direction. 
With the Laplace pressure as mentioned in Equation (2), this leads to the following expression of the Weber number:

$$
W e=\frac{\eta_{c} \dot{\gamma} R_{d}}{2 \sigma}
$$

\subsection{Laminar Extensional Flow}

When a liquid is squeezed through a small opening, and accelerated, the droplet is extended in the direction of flow (Figure 5b). This situation occurs amongst others in high-pressure homogenizers when under non-turbulent conditions are applied. During passage through the homogenizer nozzle, the droplet extends into a thread that consecutively breaks into many small droplets. This process is geared by Rayleigh-Plateau instability. In this case, the shear is exerted in the direction of the flow (with coordinate $y$ ), thus the shear rate is $\dot{\gamma}=d v_{y} / d y$, see Figure $5 \mathrm{~b}$. The definition of Laplace pressure, disruptive stress and Weber number remain as defined earlier in Equations (2)-(4).

For droplet break-up to occur, the Weber number needs to exceed a critical value. In simple shear flow, part of the energy is used to rotate the droplet, whereas in extensional flow [41] that is not the case, leading to efficient break-up. As a consequence, the critical Weber number is lower than for simple shear flow, see Figure 6, in which the classic 'Grace' curves are shown [42]. The critical Weber number shows a minimum for simple shear flow. At high viscosity ratio, the internal viscosity of the droplets resists deformation, which makes it difficult to break droplets up. At low viscosity ratio, droplets need to be deformed to a large extent, thus forming very long threads before they break (as would be the case for, e.g., foams). In a practical setting, both types of flow will occur simultaneously; which can be interpreted as critical Weber numbers that lay in between the two extremes given in Figure 6. It is good to point out that in large scale emulsification processes, much more energy is needed. Droplets that are formed are not immediately stabilized, leading to re-coalesce, and energy will be lost to heating of the product (which can be $>95 \%$ of the total energy expenditure [43]).

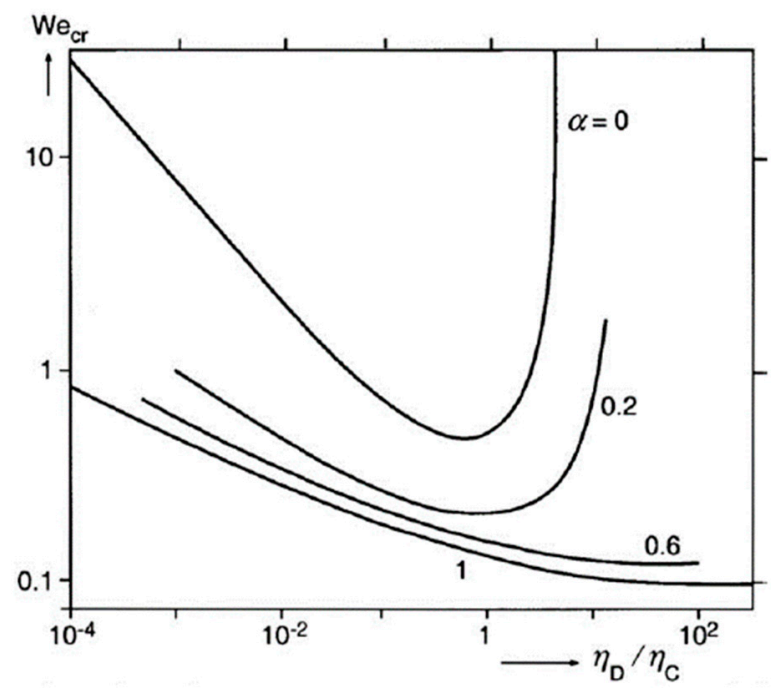

Figure 6. Critical We-numbers ( $\mathrm{We}_{\mathrm{cr}}$ ) for laminar flow conditions-plain shear flow (upper curve), and for extensional flow (lower curve) $([41,42]) . \eta_{D} / \eta_{C}$ is the ratio of the dispersed phase viscosity over the continuous phase viscosity. Re-printed with permission from author Walstra.

\subsection{Turbulent Flow}

As is clear from Figure 2, under turbulent conditions the flow is very erratic and is characterized by local fluctuations. The exact local flow conditions cannot be determined, and to average this out, the power density (symbol $\varepsilon\left(\mathrm{W} / \mathrm{m}^{3}\right.$ or $\left.\mathrm{Pa} / \mathrm{s}\right)$ is used. This can be interpreted as a measure for the average intensity of the eddies. When turbulence is still relatively low, the eddies impose shear forces 
to the surface of the droplets in a parallel direction, i.e., viscous forces. The Kolmogorov theory can be used to estimate the external disruptive force $(\tau, \mathrm{Pa})$ :

$$
\tau \approx \sqrt{\varepsilon \cdot \eta_{c}}
$$

For a Weber number defined as before, the expression now becomes [41]:

$$
W e=\frac{\tau R_{d}}{2 \sigma} \approx \frac{\sqrt{\varepsilon \eta_{c}} R_{d}}{2 \sigma}
$$

The droplet size can be estimated for these conditions using a critical Weber number of one.

For more intense turbulence, inertia of the continuous phase surrounding the droplets becomes dominant. The size of the eddies is much smaller than the droplets, and they stress the droplet surface with forces that act in perpendicular fashion. The external disruptive force can be calculated as [41]:

$$
\tau=\varepsilon^{2 / 3} R_{d}^{2 / 3} \rho_{c}^{1 / 3}
$$

With $\rho_{c}$ the density of the continuous phase. This external disruptive force can be substituted in the Weber equation. Assuming a critical value around unity, the droplet radius can again be calculated.

From the ratio of the Weber numbers for viscosity-dominated to inertia-dominated break-up, follows that the transition between the two regimes takes place when the droplets are larger than [41]:

$$
R_{d}>\frac{\eta_{c}^{2}}{\sigma \rho_{c}}
$$

\subsection{Comparison of Droplet Formation Times and Scaling Relations}

Rayner [8] has compiled various characteristics of emulsification methods (Table 2) in a useful table that we here reproduce to give a complete overview of available scaling relations.

From this table and previous sections, it is clear that droplet sizes can be estimated if flow conditions are known and a realistic value for the interfacial tension is available. This is however far from trivial to establish. In a high-pressure homogenizer, different nozzles may be used [44] that lead to various flow conditions, with a droplet residence time in the dispersing zone typically from 0.1-30 ms [45]. In a colloid mill, the residence time is comparatively much longer ( 0.1-1 s) [45], whereas in cross-flow membrane emulsification, the flow conditions are mostly laminar, and droplet formation may take as little as $15 \mathrm{~ms}$ [46]. For pre-mix membrane emulsification using metal sieves, the residence time during a single pass is around $8 \mu \mathrm{s}$ [29] and this becomes $0.01-0.3 \mathrm{~s}$ when using a packed bed system in conjunction [33]; for both systems the flow conditions are no longer laminar. From these examples it is clear that droplet formation times are very short, and thus the interfacial tension would need to be determined at similar time scales, which is far from trivial as elaborated in the next section. 
Table 2. Equations for estimating stresses exerted on droplets, expected mean particle diameters, adsorption times of surfactants, droplet deformation times, and collision times for emulsion droplets under laminar and turbulent flow conditions.

\begin{tabular}{cccc}
\hline Flow Regime & $\begin{array}{c}\text { Laminar-Viscous Shear } \\
\text { or Elongational (LV) }\end{array}$ & $\begin{array}{c}\text { Turbulent-Viscous } \\
\text { Shear Forces (TV) }\end{array}$ & $\begin{array}{c}\text { Turbulent-Inertial } \\
\text { Forces (TI) }\end{array}$ \\
\hline Re-flow & $<1000$ & $>$ approx. 2000 & $>$ approx. 2000 \\
\hline Re-droplet & $<1$ & $<1$ & $>1^{*}$ \\
\hline Mean Diameter $(d \approx) \#$ & $\frac{2 \gamma W e_{c r}}{\eta_{c} G}$ & $\frac{\gamma}{\sqrt{\varepsilon} \eta_{c}}$ & $\left(\frac{\gamma^{3}}{\varepsilon^{2} \rho_{c}}\right)^{\frac{1}{5}}$ \\
\hline External stress acting on droplets $(\sigma)$ & $\eta_{c} G$ & $\sqrt{\varepsilon \eta_{c}}$ & $\sqrt[3]{\varepsilon^{2} d^{2} \rho_{c}}$ \\
\hline Droplet deformation time scale $\left(\tau_{D E F}\right)$ & $\frac{\eta_{D}}{\eta_{c} G}$ & $\frac{\eta_{D}}{\sqrt{\varepsilon} \eta_{c}}$ & $\frac{\eta_{D}}{\sqrt[3]{\varepsilon^{2} d^{2} \rho_{c}}}$ \\
\hline Duration of disruptive stresses $\left(\tau_{D I S}\right)$ & $\frac{1}{G}$ & $\sqrt{\frac{\eta_{c}}{\varepsilon}}$ & $\frac{1}{2}\left(\frac{\gamma^{2} \rho_{c}}{\varepsilon^{3}}\right)^{\frac{1}{5}}$ \\
\hline Surfactant adsorption time scale $\left(\tau_{A D S}\right)$ & $\frac{6 \pi \Gamma}{d m_{c} G}$ & $\frac{6 \pi \Gamma}{d m_{c}} \sqrt{\frac{\eta_{c}}{\varepsilon}}$ & $\frac{\Gamma}{m_{c}} \sqrt[3]{\frac{\rho_{c}}{d \varepsilon}}$ \\
\hline Droplet collision time scale $\left(\tau_{C O L}\right)$ & $\frac{\pi}{8 G \phi}$ & - & $\frac{1}{15 \phi} \sqrt[3]{\frac{d^{2} \rho_{c}}{\varepsilon}}$ \\
\hline
\end{tabular}

Adapted from: ([11,43,47]) Symbols: We = Weber number (see text); Re = Reynolds number (see text); Re-droplet $=$ Reynolds number but with the droplet size as characteristic dimension; $\Gamma=$ surface excess of surfactant $\left(\mathrm{mol} \mathrm{m}^{-2}\right) ; \varepsilon=$ power density $\left(\mathrm{J} \mathrm{s}^{-1} \mathrm{~m}^{-3}\right) ; d=$ droplet diameter $(\mathrm{m}) ; \gamma=$ interfacial tension $\left(\mathrm{J} \mathrm{m}^{-2}\right)$; $\eta=$ viscosity (Pa s); $G=$ velocity gradient $\left(\mathrm{s}^{-1}\right) ; m_{c}=$ surfactant concentration in the continuous phase $\left(\mathrm{mol} \mathrm{m}^{-3}\right)$; $\tau=$ characteristic time (s); $\sigma=$ stress $(\mathrm{Pa}) ; \rho=$ density $\left(\mathrm{kg} \mathrm{m}^{-3}\right)$. Subscripts: $\mathrm{d}=$ dispersed phase; $\mathrm{c}=$ continuous phase; $\mathrm{DEF}=$ deformation; $\mathrm{ADS}=$ adsorption; $\mathrm{cr}=$ critical value for droplet break-up. Notes: ${ }^{*}$ For $d>\eta_{c}^{2} /\left(\gamma \rho_{c}\right)$. \# Only if $\eta_{d} \gg \eta_{c}$. Table reprinted with permission from CRC Press [8].

\section{Interfacial Tension Measurement}

\subsection{Classical Techniques}

The choice for which interfacial tension value to use in the equations in Table 2 is mostly limited to the two that can be assessed with accuracy, that of an interface without any surface-active components, and that of an interface which is in equilibrium with the surface-active component. However, at the sort time-scales usually encountered in homogenization processes, any value in between may occur, and the actual value depends on amongst others, the diffusion coefficient, adsorption/desorption kinetics and possible structural rearrangements that are typical for high-molecular weight surface-active components such as proteins and polymers (e.g., [48]).

Classical technologies to measure interfacial tension are the Wilhelmy plate, the droplet volume tensiometer, and the spinning drop method specifically for systems with very low interfacial tension. The Wilhelmy plate method revolves around a plate that is brought into the interface, and onto which the interfacial tension acts. The interfacial tension force can be measured with an accuracy of $0.01 \mathrm{mN} / \mathrm{m}$ when the method is carried out carefully. The droplet volume tensiometer is widely used to measure interfacial tension at fluid interfaces [49-51], and is based on shape analysis of a millimeter-size Laplacian droplet of one phase that is formed at the tip of a needle and immersed in the other phase. The shape of such a droplet depends on the balance between gravity and interfacial tension forces; it is important that their ratio is sufficiently large such that the droplet is deformed into a pear shape (i.e., bond number typically higher than 0.1). The interfacial tension can then be determined by analyzing the shape of the, now deformed, droplet through a numerical fit of the Laplace pressure. The first measurement point is normally obtained after slightly less than one second, and measurements may be conducted for periods of several hours, and can be used to investigate competitive adsorption, and replacement of one surface-active component by another (e.g., [50,51]). The time-scale for such a diffusion-driven process is orders of magnitude longer than typical adsorption times encountered for most emulsifiers in commercial homogenizers, where transport is dominated by convection. For low interfacial tensions, the spinning droplet method is used. In a capillary, a lower-density droplet is placed in the other higher-density liquid, and the capillary is subsequently spun around its axis at known velocity. The higher-density bulk phase 
moves towards the tube walls due to centrifugal forces, leading to elongation of the droplet. From this shape change of the droplet, the interfacial tension can be calculated for values as low as $10^{-3} \mathrm{mN} / \mathrm{m} \mathrm{[4]}$.

The previously mentioned methods are not that suited to measure at (sub-)millisecond time scales as they can occur in large-scale emulsification devices. In limited cases, Rayleigh instabilities can be used (dynamic jet). A new class of techniques is currently developed, based on microfluidic devices, in which droplets can be made in the millisecond range. Here, we discuss how they can be used to elucidate interfacial tension.

\subsection{Dynamic Interfacial Tension Measurement with Microfluidic Devices}

Microfluidic devices can be used to get insights on surfactant behavior; as recently reviewed by $[52,53]$. These devices are mostly used for direct emulsification; for an extensive description of microfluidic devices and the various products (e.g., double emulsions, particles and capsules), please consult the review by Vladisavljevic, Kobayashi, and Nakajima [20] that also covers membrane emulsification. Further, we recommend the work of Garstecki et al. [54] Wehking et al. [55], Steegmans [56] for T-junctions. For Y-junctions, please see Steegmans et al. [57], for flow focusing Anna et al. [58], and for straight through microchannels the teams of Sugiura [59] and Kobayashi [60].

Microfluidic methods for interfacial tension measurement can be based on droplet size [61-63], pressure drop (measured by an online commercial sensor [64] or, very recently, an on-chip sensor channel [65]), droplet deformability [66], pH change related to adsorption kinetics [67], or the jetting/dripping transition [68]. Measurements based on droplet size have been performed in different microfluidic geometries: Steegmans et al. [61] used a cross-flow Y-junction (Figure 7A), Wang et al. [62] a cross-flow T-junction (Figure 7B), and $\mathrm{Xu}$ et al. [63] a coaxial device (Figure 7C). In these devices, droplet size depends on the balance between the shear exerted by the continuous phase and the interfacial tension. The ratio between these forces is captured by the Capillary number (Ca). All these authors used the droplet size at the time of droplet formation to determine the interfacial tension in from a Capillary number. A relation between pressure drop and radius of the growing droplet (Laplace pressure) was used by Wang et al. [64] (Figure 7D). Droplet deformation was used by Brosseau et al. [66] who directed droplets through 121 expansion chambers (Figure 7E), and related the evolution of interfacial tension to droplet velocity, and droplet geometry. Typical droplet sizes and time-scales used in these measurements are given in Table 3.

A

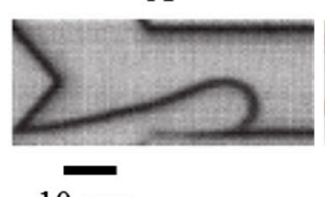

$10 \mu \mathrm{m}$
$\mathrm{B}$

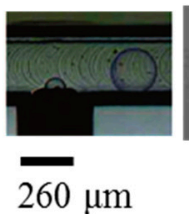

$\mathrm{C}$

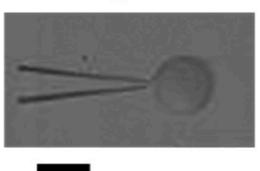

$8 \mu \mathrm{m}$

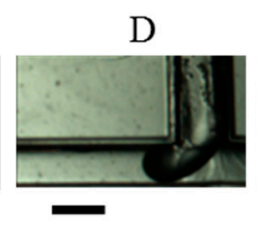

$923 \mu \mathrm{m}$

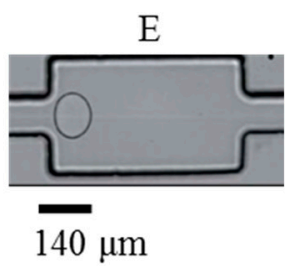

Figure 7. Microscopic images during or after interfacial tension measurement based on droplet size (A) [61], (B) [62], and (C) [63]; pressure drop (D) [64]; and droplet deformation (E) [66]. Images reprinted with permission of Springer [69].

Table 3. Overview of microfluidic tensiometric methods, and characteristic values.

\begin{tabular}{cccc}
\hline Reference & Method & Droplet Diameter $(\mu \mathrm{m})$ & Time-Scale $(\mathbf{m s}) \mathbf{a}$ \\
\hline Steegmans et al. [61] & Size & $8-13$ & $0.5-10$ \\
Wang et al. [62] & Size & $160-270$ & $20-70$ \\
Xu et al. [63] & Size & $10-180$ & $1-130$ \\
Wang et al. [64] & Pressure drop & $400-800$ & $10-8000$ \\
Brosseau et al. [66] & Deformability & $90-120$ & $10-2000$
\end{tabular}

a time between start droplet formation and measurement; table reprinted with permission form the author [70]. 
With the method of Steegmans et al. [61], the smallest droplets and time-scales can be assessed [62,66,71], which are both relevant for large-scale processes. The effects of process and ingredient conditions have been investigated and are described in more detail in the following section.

\subsection{Y-Junction Used to Elucidate Interfacial Tension at (Sub)-Millisecond Time Scale}

The microfluidic geometry used is a Y-junction; here the to-be-dispersed phase is pushed from one leg of the $\mathrm{Y}$ into the continuous phase that distorts it, and ultimately breaks off droplets in the main channel (Figure 8). Droplet growth consists of two stages: first the droplet liquid is pushed into the main channel, and second the neck starts forming and the droplet grows while feeding from the neck. The second stage has less effect on the total droplet volume than reported for T-junctions [56,72]. This makes the Y-junction a more valid option for dynamic interfacial tension measurements.

\subsubsection{Droplet Formation Mechanism}

For T-junctions, Garstecki et al. [54] introduced various mechanisms for droplet formation: dripping, transition, and jetting, and these can also be applied to Y-junctions. In the dripping regime, the droplets form very close to the pore, whereas in jetting the neck is dragged along with the continuous phase before snapping off. In the work of Muijlwijk and co-workers [73] the transition between these regimes was linked to the length of the neck at the second-to-last frame before detachment (comparable to image 4 in Figure 8). For the analysis of the interfacial tension, only droplets in the dripping regime were used (neck length of at most 1\%; Figure 9, right). The volume of the droplet was related to the dispersed phase flow and from this linear graph (Figure 9, left) it is clear that at low to-be-dispersed phase flows the volume of the droplet is mostly determined by the volume of the liquid that is immediately pushed into the main channel (growth stage), and not so much by growth that takes place thereafter (detachment stage). To be complete, it is good to mention that similar phases have been described for co-flow devices [74].

Continuous phase

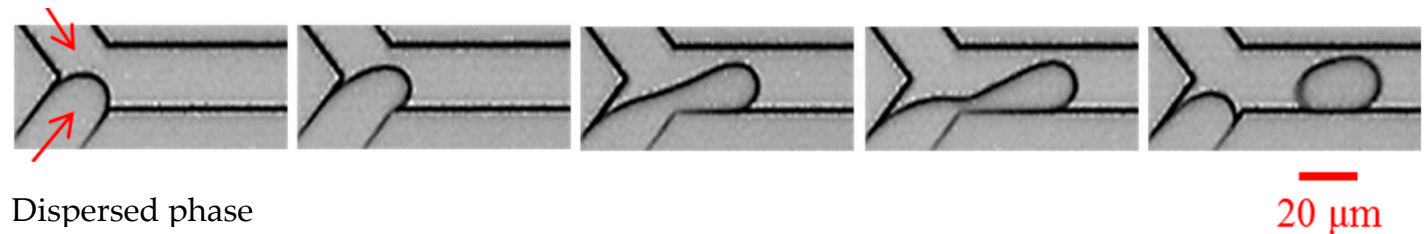

Figure 8. Oil droplet formation in a Y-junction microfluidic device (reprinted with permission from Elsevier [73]).
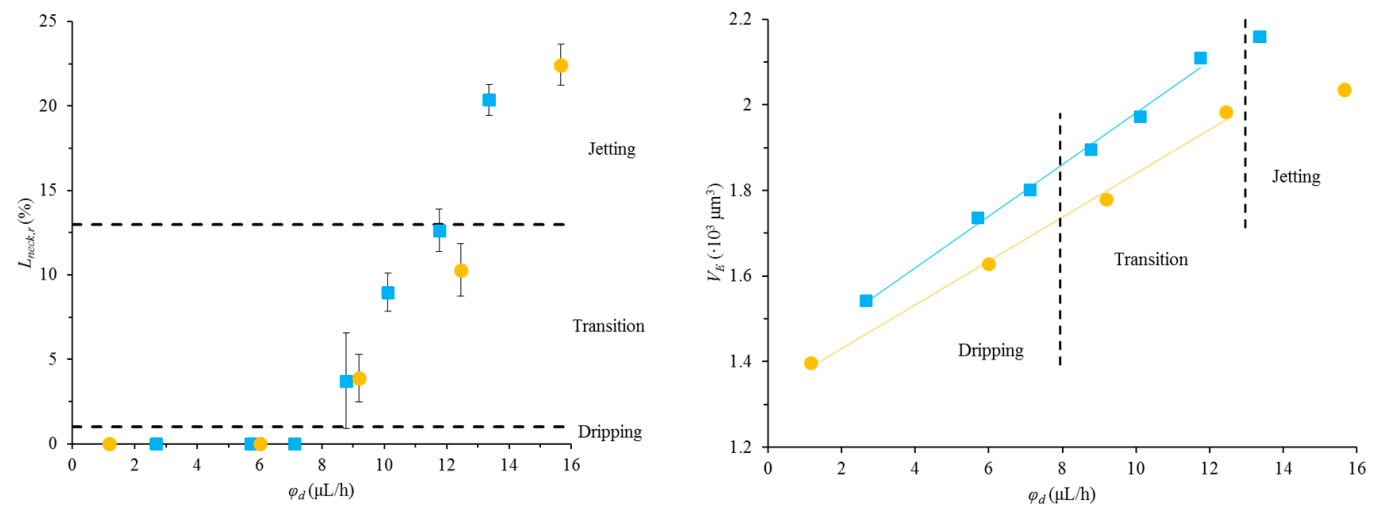

Figure 9. Left: the relative neck length $($ Lneck,r) in the second-to-last-frame-before-detachment of droplets formed in water at flow rates of $75.7 \pm 1.5 \mu \mathrm{L} / \mathrm{h}(\boldsymbol{\bullet})$ and $92.2 \pm 1.5 \mu \mathrm{L} / \mathrm{h}(\bullet)$. The error bars indicate the standard deviation. Right: the experimentally determined droplet volume $\left(V_{E}\right)$ at a water flow rate of $75.7 \pm 1.5 \mu \mathrm{L} / \mathrm{h}(\boldsymbol{\bullet})$ and $92.2 \pm 1.5 \mu \mathrm{L} / \mathrm{h}(\bullet)$ as a function of the dispersed phase flow rate $(\varphi d)$ with linear fits (both graphs are reproduced from [73]). Reprinted with permission from Elsevier. 


\subsubsection{Model Development}

In order to be widely applicable, the Y-junction needed to be calibrated. Using the basic relations shown in Figure 9 (right), the droplet size was predicted with the following equation [73]:

$$
V=b \sqrt{\frac{1}{C a}}+\frac{c}{v_{c}} \varphi_{d}
$$

The volume added during the detachment stage scaled with the inverse velocity of the continuous phase at the junction $\left(v_{c}\right)$, and was proportional with the dispersed phase flow, $\Phi_{d}$. The volume added during the growth stage scaled with the inverse square root of the capillary number, so with $\mathrm{Ca}^{-0.5}$ $\left(C a=\frac{\eta_{c} v_{c}}{\sigma}\right.$; with $\eta_{c}$ the continuous phase viscosity (Pa s), $v_{\mathcal{C}}$ the continuous phase velocity $(\mathrm{m} / \mathrm{s})$, and $\sigma$ the interfacial tension $(\mathrm{N} / \mathrm{m}))$. Further, $b$ and $c$ are proportionality constants that were found to be not correlated, which is indicative for the model's robustness.

Similar scaling relations have been found for cross-flow membrane emulsification, for droplets formed via a one-step mechanism (corresponds to first part of the model $[75,76]$ ). In the work of van der Graaf and co-workers $[77,78]$ a factor of -0.75 was reported for T-junctions in which a two-step mechanism also occurred. The difference between the junctions is most probably related to facilitation of break up by the angle under which the two phases meet. To be complete, it is good to mention that in the literature, also the Weber number has been suggested to play a role in droplet formation in co-flow devices [74].

\subsubsection{Model Validation}

The validity of Equation (9) was tested, using liquids with different static interfacial tension (so, in absence of surface-active components) and viscosities [61,73]. It is clear that the model captures the behavior of all these liquids well (Figure 10).

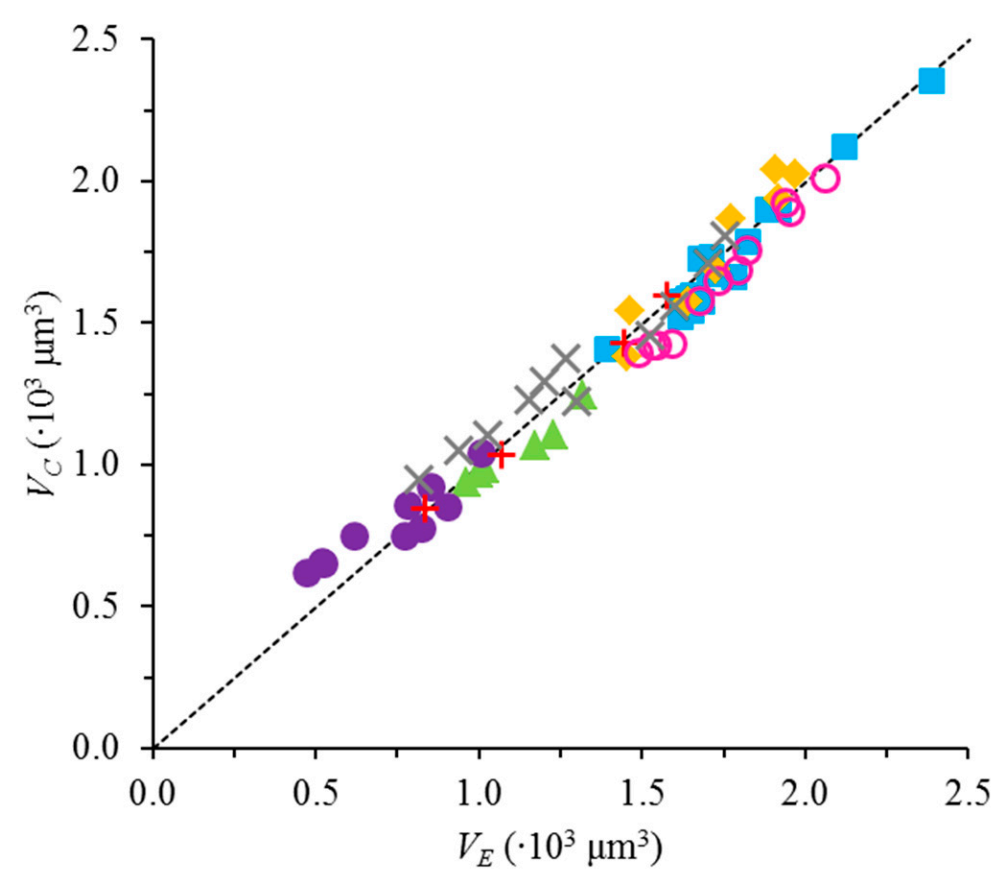

Figure 10. Parity plot of experimentally determined volume of droplets formed in: water (घ), $9 \%$ ethanol

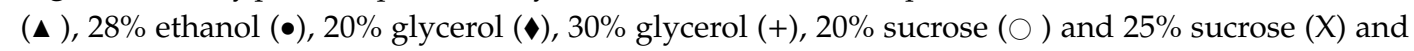
values predicted using Equation (9). The dashed line represents the line of parity; [73], Copyright Elsevier). Properties of the liquids are shown in Table 4. Reprinted with permission from Elsevier. 
Table 4. Viscosity and interfacial tension with hexadecane at $20^{\circ} \mathrm{C}$.

\begin{tabular}{ccc}
\hline Sample & $\boldsymbol{\eta}$ (mPa.s) & $\sigma o w \mathbf{~} \mathbf{m N} / \mathbf{m})$ \\
\hline Water & 0.98 & 44.0 \\
9.0\% ethanol & 1.42 & 31.6 \\
$28.0 \%$ ethanol & 2.52 & 16.0 \\
$20.0 \%$ glycerol & 1.78 & 41.1 \\
$30.0 \%$ glycerol & 2.52 & 36.7 \\
$20.0 \%$ sucrose & 2.07 & 42.7 \\
$25.0 \%$ sucrose & 2.42 & 42.0 \\
\hline
\end{tabular}

\subsubsection{Application in Dynamic Systems}

Dynamic interfacial tension during droplet formation was studied using hexadecane, and water in which sodium dodecylsulphate (SDS) was dissolved as the surface-active component. After rewriting Equation (9) into Equation (10), the detected droplet volume can be used to calculate the interfacial tension at the time of droplet snap-off [73]:

$$
\sigma=\eta_{c} v_{c}\left(\frac{V-\frac{c}{v_{c}} \varphi_{d}}{b}\right)^{2}
$$

For SDS concentrations ranging from 0.01-0.5, the results shown in Figure 11 were obtained. For comparison, data obtained with a droplet volume tensiometer are shown on the left (solid lines).

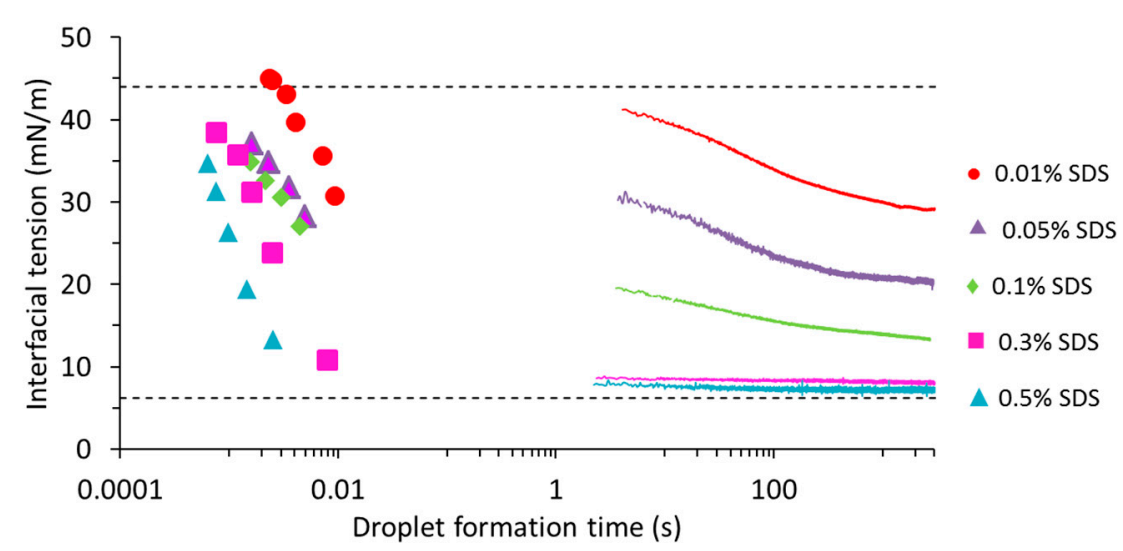

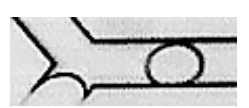

$0.01 \%$

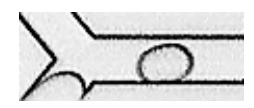

$0.1 \%$

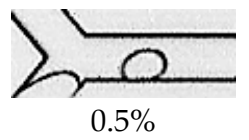

Figure 11. Interfacial tension at the hexadecane-water interface with various sodium dodecylsulfate (SDS) concentrations in the aqueous phase, as measured with a microfluidic Y-junction (symbols) and with a droplet volume tensiometer (solid lines). The dotted lines represent the equilibrium interfacial tensions between hexadecane and water (top) and between hexadecane and a 1\% wt. SDS solution (bottom). On the right images of droplets made for the indicated concentrations at a droplet formation time of 1.5 millisecond (channel width $=18 \mu \mathrm{m}$, channel depth $=5 \mu \mathrm{m}$ ). Adapted from Muijlwijk et al. [73], with permission from Elsevier.

The data point shown on the left in Figure 11 represent the interfacial tension measurements done with the Y-junction at droplet formation times as short as 0.4 millisecond, while the droplet volume tensiometer results shown on the right take place at much longer time scales. As references, horizontal lines are used in the graph, that correspond with the interfacial tension of the hexadecane/water interface (top), and that of the interfacial tension at full surface coverage by SDS (bottom). As mentioned previously, these measurements are all done in the dripping regime. Visuals of droplets obtained at the Y-junction are shown on the far right for a droplet formation time of 1.5 millisecond.

As could be expected, at short droplet formation times the interfacial tension is high, and when allowed more time, the interfacial tension becomes lower (Figure 11). Furthermore, the surfactant 
concentration plays an important role, with high concentrations leading to fast reduction in interfacial tension. What is important to point out is that this method works at droplet formation rates between 1000 and 10,000 droplets per second, and thus allows evaluation of dynamic interfacial tension at sub-millisecond time scales, and that is very close to the time scales as they would occur in conventional emulsification devices.

The results for the droplet volume tensiometer are shown on the right of Figure 11. The trends are as expected, with a reduction of interfacial tension in time, and high concentrations of SDS leading to faster interfacial tension reduction. However, it should be noted that the time intervals are orders of magnitude higher. SDS adsorption in the droplet volume tensiometer is fully diffusion-driven, and although it is often thought that microfluidic devices would be governed by diffusive processes, the results shown in the left of Figure 11 indicate that mass transfer is much faster, probably due to the very fast retraction of the oil column after droplet formation, which enhances mass transfer (probably in both phases) [79].

\subsubsection{Toward Food Applications}

Y-junctions are also suited to study more complex systems and elucidate the various effects that play a role. These conclusions would be based on a large number of observations, which allows for detailed statistical analysis. For example, food grade water-soluble surfactants (Tween 20), oil-soluble surfactants (Span 20), and combinations thereof were tested by Muijlwijk et al. [80]. From these observations it was clear that emulsifier transport was not diffusion limited [79], but dominated by convection (both in the continuous and dispersed phases).

In principle, the $\mathrm{Y}$-junction can be used for rapid screening of emulsion components (initial results are available for proteins [81]), and most probably, the obtained data can be used to predict effects occurring in the more classic emulsification devices that were discussed earlier in this review, as has already been done for membrane emulsification to some extent [82]. The droplet formation times are rather similar (as is discussed further in the outlook section) but the mass transfer conditions may be different, and that is still a point of attention.

Away from the value of the interfacial tension, the stability of the droplets after formation is also very important, and to investigate that, Krebs et al. [83-85] developed a microfluidic combination of droplet generator and coalescence cell. Initially, this device was used for simple surfactants; in the next section we show results obtain when using proteins as surface-active components.

\subsubsection{Combination of Interfacial Tension and Coalescence in a Microfluidic Device}

In Figure 12, the layout of a combined microfluidic device for droplet formation and droplet coalescence is presented. On the left, a T-junction is visible that is used to make the droplets, after which they move through a meandering channel. The length of this channel can be varied, therewith allowing different times for emulsifier adsorption to take place, before the droplets move into the coalescence chamber in which they slow down, collide and possibly coalesce. Images were taken at the beginning and end of the chamber, as indicated by the two rectangles in Figure 12 [86].

Some illustrative results are shown in Figure 13, in which the length of the meandering channel, as was the protein concentration was varied. In this case whey protein isolate was used, a commonly encountered food emulsifier, and the coalescence frequency is plotted as function of the adsorption time which is taken as the droplet residence time in the meandering channel. At low concentrations and short residence times coalescence takes place readily, as is also illustrated by the photos on the right. But when given sufficient time, even at low concentrations, coalescence occurred hardly, if at all. To prevent coalescence, the crucial factor is not the decrease of surface tension, but rather a sufficient coverage of the interface by emulsifiers in order to slow drainage and possibly provide surface elasticity. This was also the case for Pickering emulsions that are stabilized by particles that need to be present at sufficient amounts at the interface, and that can only be efficient when brought into the interface with sufficient force [87]. In this latter case, the coalescence microfluidic setup was instrumental in 
establishing the non-monotonic effect of particles on droplet stability: a too low particle concentration led to promoted coalescence due to droplet-droplet bridging, i.e., a destabilizing effect, whereas at higher particle concentrations, stable droplets could be formed.

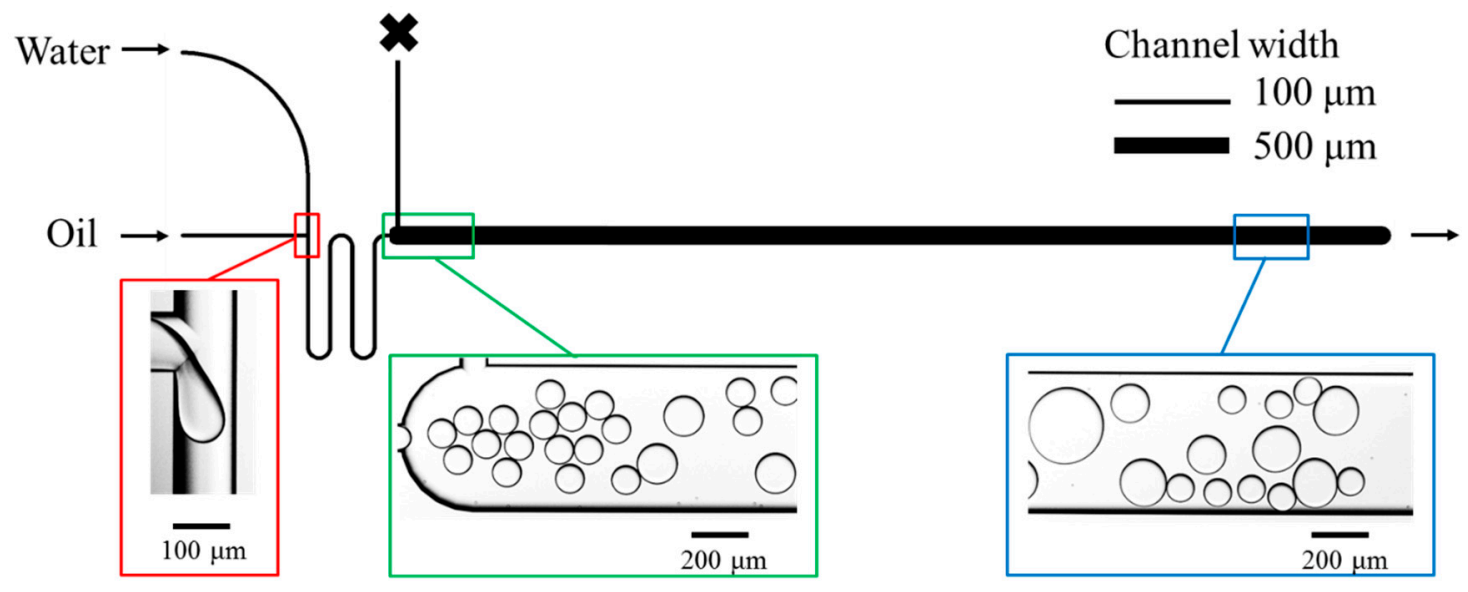

Figure 12. Layout of the microfluidic chip with a T-junction as droplet formation unit (left) a meandering adsorption channel length of $14.8 \mathrm{~mm}$, and a coalescence chamber. The rectangles indicate the regions from which images were recorded and show examples of microscope images [86]. Reprinted with permission from Elsevier.

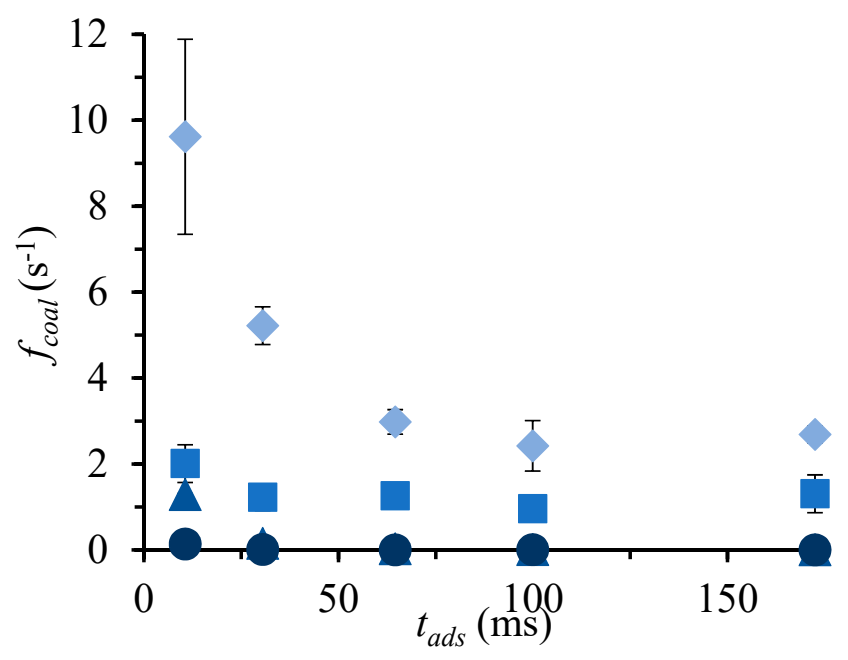

(a)

$$
t_{\text {ads }}=173 \mathrm{~ms}
$$

Whey protein isolate (wt. \%)

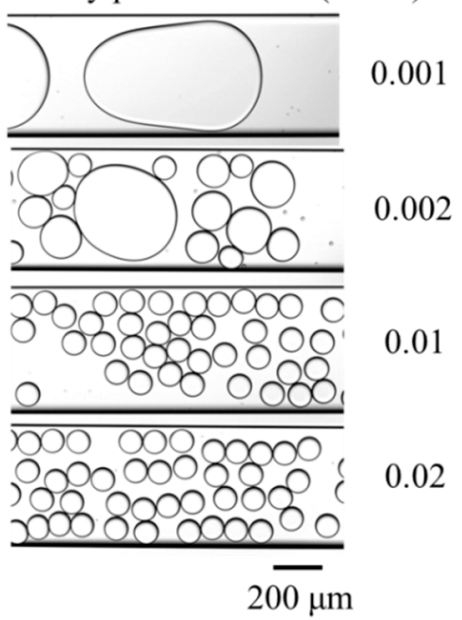

(b)

Figure 13. (a) Mean coalescence frequency and microscope images from the outlet of the collision channel with $0.001(\bullet), 0.002(\boldsymbol{\square}), 0.01(\boldsymbol{\Delta})$, and $0.02(\bullet)$ wt \% whey protein isolate. The error bars indicate the standard deviation of the three recordings taken per measurement [86]. (b) Images taken at difference protein concentrations for an adsorption time of 173 milliseconds. Reprinted with permission form Elsevier.

The typical concentrations that were used in the microfluidics are quite lower than those applied in food emulsion formulation, and as described earlier this could have to do with the fact that in classic emulsification equipment, a lot of re-coalescence takes place [86]. What also needs to be kept in mind is that the observation time in the microfluidic devices is very short, and that coalescence takes place under much more controlled conditions as would be the case in, e.g., high-pressure homogenizers. Still the technique allows for analysis of very subtle changes, e.g., due to oxidation of the proteins $[70,88]$, 
or through differences in composition of the emulsifier mixture $[73,79]$. The translation of the results obtained in this way to large scale emulsification devices is still a next step to take [89].

\section{Comparison of Time Scales}

In case emulsifiers stabilize the interface before droplet collision occurs, emulsification is most efficient, because re-coalescence is prevented. A summary of typical droplet formation times as they occur in various emulsification devices is given in Table 5 , including the microfluidic devices presented earlier. The time for adsorption in the coalescence microfluidic chips, which is the sum of droplet formation time and adsorption time in the meandering channel, is relatively high. It compares well with the typical time scales as they occur in colloid mills, direct membrane emulsification, and spontaneous microfluidic emulsification. Y-junction microfluidics allow study of much faster processes, and compare well with time scales that occur during high-pressure homogenization, premix membrane emulsification, and of course shear-based microfluidic emulsification.

For emulsions formed with colloid mills, Karbstein and Schubert [90] reported higher stability against coalescence than for emulsions formed in toothed disc dispersing machines and high-pressure homogenizers, because the time for emulsifier adsorption before collision in the colloid mill is longer, and this is supported by our findings in the microfluidic devices. Kolb et al. [91] designed a high-pressure nozzle with a turbulence chamber to prolong the residence time in the dispersing zone, and this indeed led to less re-coalescence compared to standard nozzles, which could be an early indication that our measurements are able to assess also these conditions.

Re-coalescence is expected to be much lower for microfluidic devices than conventional homogenization because more time is allowed for interface stabilization to take place. This could also be a clear selling point for scaling up microfluidic devices. Some of the design criteria could be taken from the microfluidic observations that are also highlighted in this paper, such as the interfacial tension as function of the interface expansion rate.

Table 5. Adsorption time range of various emulsification devices and of the used microfluidic devices ([70]; reprinted with permission from the author).

\begin{tabular}{cc}
\hline Emulsification Device & Adsorption Time Range (s) \\
\hline High-pressure homogenizer & $10^{-4}-10^{-2}[45]$ \\
Colloid mill & $10^{-1}-100[45]$ \\
Direct membrane emulsification & $10^{-2}[46]$ \\
Pre-mix membrane emulsification & $10^{-6}-10^{-1}[28,31,33]$ \\
Spontaneous microfluidic emulsification & $10^{-2}-10^{-1}[92]$ \\
Shear-based microfluidic emulsification & $10^{-4}[93]$ \\
Y-junction & $10^{-4}-10^{-2}[70,94]$ \\
Coalescence channel & $10^{-2}-10^{-1}[70]$ \\
\hline
\end{tabular}

Shear-based microfluidic devices are known to be very accurate in droplet size production when used as a single unit; however, up-scaled devices are very hard to find, or they produce relatively large droplets (diameter $=91 \mu \mathrm{m}$ ) $[93,95,96]$. With spontaneous microfluidic methods, such as the EDGE (also termed step) $[97,98]$ and straight-through devices [60,99-101], smaller droplets can be formed (diameter $=4-10 \mu \mathrm{m}$ ) and the size is less sensitive to changes in process conditions [89,92,95,102]. Productivity of these devices makes them suitable for low volume, high added-value applications at small scale, especially the so-called EDGE (Edge-based Droplet GEneration) family of devices, which is unique in its ability to product multiple droplets from one droplet formation unit [89,103,104].

Besides emulsions, it is also expected that other two-phase systems such as foams will benefit greatly from insights obtained through the use of microfluidics [105]. Compared to emulsions, for which only $0.005 \mathrm{wt} \% \beta$-lactoglobulin was needed for stabilization [70], a much higher concentration was needed for foams $(>0.1 \mathrm{wt} \%)$, which may be related to the expansion rate during bubble formation that is much higher than for emulsions that have a higher dispersed-phase viscosity. Bubbles have 
dimpling instabilities that are more prominent than in droplets, which facilitates film rupture [106,107]. Last but not least, $\beta$-lactoglobulin may have a higher affinity for oil than for air, which may lead to a higher interfacial protein concentration with a more compact and protective structure at the oil-water interface [108-112]. To distinguish between these effects, more observations are needed, and that is possible combining high speed imaging and microfluidic observations.

Alternatively, the coalescence cells can also be applied for conditions at which demulsification is needed. In that case the devices are instrumental at identifying conditions that allow for coalescence to still take place, as would be very relevant in the oil and gas industry $[85,113]$.

\section{Concluding Remarks}

Although it is widely accepted that interfacial tension is an important parameter in the formation of emulsions and other multi-phase products, and many scaling relations are available that use this parameter, determining its actual value at the moment of droplet formation is far from trivial. Current methods simply lack the resolution to determine interfacial tension at relevant times, since their time scales are orders of magnitude longer compared to those involved in large-scale emulsification devices.

In this paper we highlighted progress made using microfluidic devices that are able to measure interfacial tension at very short time scales, and under conditions that are not ruled by diffusive emulsifier transport, as is the case in the classic methods such as droplet volume tensiometry. These capabilities bring observations of dynamic interfacial tension to a next level, and gives them predictive power for large scale processing.

The interfacial tension as such is not indicative for emulsion stability, for that the combination of droplet formation and coalescence is needed. In microfluidic coalescence devices, droplet formation and droplet coalescence can be decoupled, and in this way, product formulation and stability can be investigated separately, albeit in one device.

We expect that the current developments in microfluidics will bring emulsion product formulation to a next level. Although the price of microchips is currently not very low, it is accessible for many labs (typically 100-200 euro per chip). The main investments would most probably be in a good high-speed camera in combination with an excellent microscope. Furthermore, it is good to point out that microchip production will increasingly become a process that is available for many. We currently work with 3D printing, and we are able to make structures in the order of 1-10 micrometers routinely. This makes us highly flexible in our designs, and will reduce production time considerably compared to the traditional cleanroom approach.

Besides liquid-liquid systems, it is expected that many of the discovered principles can be used in other dispersion systems, e.g., foams [105], aqueous two-phase systems [114], etc. For example, the surface elasticity can also be monitored in microfluidic systems, and although this is mostly done for surfactant systems, a lot of progress has also been made in this field $[115,116]$. In that respect, the findings presented here are only the tip of the proverbial iceberg of options that microfluidic technology has to offer for emulsification research $[69,89]$.

Author Contributions: K.S. wrote the paper, together with J.d.R. and C.B.-C. All authors were involved in projects in which the microfluidic tools that are discussed were developed. All authors have read and agreed to the published version of the manuscript.

Funding: This research received no external funding.

Conflicts of Interest: The authors declare no conflict of interest.

\section{References}

1. Tadros, T. Applied Surfactants: Principles and Applications; Wiley: Hoboken, NJ, USA, 2006; ISBN 9783527306299.

2. Friberg, S.; Larsson, K. Food Emulsions, 4th ed.; Friberg, S., Larsson, K., Sjöblom, J., Eds.; Dekker: New York, NY, USA, 2004; ISBN 0824799836.

3. Hiemenz, P. Principles of Colloid and Surface Chemistry; Marcel Dekker, Inc.: New York, NY, USA, 1986. 
4. Hiemenz, P.C.; Rajagopalan, R. Principles of Colloid and Surface Chemistry; Marcel Dekker Inc.: New York, NY, USA, 1997.

5. Chan, D.Y.C.; Klaseboer, E.; Manica, R. Film drainage and coalescence between deformable drops and bubbles. Soft Matter 2011, 7, 2235-2264. [CrossRef]

6. Stubenrauch, C.; Von Klitzing, R. Disjoining pressure in thin liquid foam and emulsion films-New concepts and perspectives. J. Phys. Condens. Matter 2003, 15237, 1197-1232. [CrossRef]

7. Chesters, A.K. The modelling of coalescence process in fluid-liquid dispersions: A Review of Current Understanding. Chem. Eng. Res. Des. 1991, 69, 259-270.

8. Rayner, M. Scales and Forces in Emulsification. In Engineering Aspects of Food Emulsification and Homogenisation; Rayner, M., Deymek, P., Eds.; Taylor \& Francis: Boca Raton, FL, USA, 2015; pp. 3-30.

9. Van der Zwan, E.A. Emulsification with Microstructured Systems: Process Principles; Wageningen University: Wageningen, The Netherlands, 2008.

10. Smulders, P. Formation and Stability of Emulsions Made with Proteins and Peptides; Wageningen University: Wageningen, The Netherlands, 2000.

11. Walstra, P.; Smulders, P.E. Emulsion formation. In Modern Aspects of Emulsion Science; Binks, B.P., Ed.; Royal Society of Chemistry Cambridge: Cambridge, UK, 1998; pp. 56-99.

12. Kissling, K.; Schütz, M.; Piesche, S. Numerical investigation of the flow field and the mechanisms of droplet deformation and break-up in a high-pressure homogenizer. In Proceedings of the 8th World Congress Chemical Engeneering, Montreal, QC, Canada, 23-27 August 2009.

13. Kohler, K. Simultanes Emulgieren und Mischen; Logos Verlag: Berlin, Germany, 2010.

14. Roos, Y.H.; Fryer, P.J.; Knorr, D.; Schuchmann, H.P.; Schroën, K.; Schutyser, M.A.I.; Trystram, G.; Windhab, E.J. Food Engineering at Multiple Scales: Case Studies, Challenges and the Future-A European Perspective. Food Eng. Rev. 2016, 8, 91-115. [CrossRef]

15. Urban, K.; Wagner, G.; Schaffner, D.; Röglin, D.; Ulrich, J. Rotor-Stator and Disc Systems for Emulsification Processes. Chem. Eng. Technol. 2006, 29, 24-31. [CrossRef]

16. Van Der Schaaf, U.S.; Karbstein, H.P. Fabrication of Nanoemulsions by Rotor-Stator Emulsification; Elsevier Inc.: Amsterdam, The Netherlands, 2018; ISBN 9780128118382. [CrossRef]

17. Canselier, J.P.; Delmas, H.; Wilhelm, A.M.; Abismaïl, B. Ultrasound Emulsification-An Overview. J. Dispers. Sci. Technol. 2002, 23, 333-349. [CrossRef]

18. Behrend, O.; Schubert, H. Influence of hydrostatic pressure and gas content on continuous ultrasound emulsification. Ultrason. Sonochem. 2001, 8, 271-276. [CrossRef]

19. van Zwieten, R.; Verhaagen, B.; Schroën, K.; Fernández Rivas, D. Emulsification in novel ultrasonic cavitation intensifying bag reactors. Ultrason. Sonochem. 2017, 36, 446-453. [CrossRef]

20. Vladisavljevic, G.T.; Kobayashi, I.; Nakajima, M.; Vladisavljević, G.T.; Kobayashi, I.; Nakajima, M. Production of uniform droplets using membrane, microchannel and microfluidic emulsification devices. Microfluid. Nanofluid. 2012, 13, 151-178. [CrossRef]

21. Eisner, V. Emulsion Processing with a Rotating Membrane (ROME). Technology 2007, 17153. [CrossRef]

22. Aryanti, N.; Williams, R.A.; Hou, R.; Vladisavljevic, G.T. Performance of rotating membrane emulsification for o/w production. Desalination 2006, 200, 572-574. [CrossRef]

23. Schröder, V.; Behrend, O.; Schubert, H. Effect of dynamic interfacial tension on the emulsification process using microporous, ceramic membranes. J. Colloid Interface Sci. 1998, 202, 334-340. [CrossRef]

24. Lee, L.L.; Niknafs, N.; Hancocks, R.D.; Norton, I.T. Emulsification: Mechanistic understanding. Trends Food Sci. Technol. 2013, 31, 72-78. [CrossRef]

25. Gijsbertsen-Abrahamse, A.J.; Van Der Padt, A.; Boom, R.M. Status of cross-flow membrane emulsification and outlook for industrial application. J. Memb. Sci. 2004, 230, 149-159. [CrossRef]

26. Lambrich, U.; Schubert, H. Emulsification using microporous systems. J. Memb. Sci. 2005, 257, 76-84. [CrossRef]

27. Vladisavljevic, G.T.; Williams, R.A. Recent developments in manufacturing emulsions and particulate products using membranes. Adv. Colloid Interface Sci. 2005, 113, 1-20. [CrossRef]

28. Nazir, A.; Schroën, K.; Boom, R. Premix emulsification: A review. J. Memb. Sci. 2010, 362, 1-11. [CrossRef]

29. Nazir, A.; Schroën, K.; Boom, R. High-throughput premix membrane emulsification using nickel sieves having straight-through pores. J. Memb. Sci. 2011, 383, 116-123. [CrossRef] 
30. Nazir, A.; Schroën, K.; Boom, R. The effect of pore geometry on premix membrane emulsification using nickel sieves having uniform pores. Chem. Eng. Sci. 2013, 93, 173-180. [CrossRef]

31. Schroën, K.; Nazir, A. Emulsification with Microsieves and Other Well-Defined Microstructured Systems. In Engineering Aspects of Food Emulsification and Homogenization; CRC Press, Food Process Engineering Group, Department of Agrotechnology and Food Sciences, Wageningen University: Wageningen, The Netherlands, 2015; pp. 235-254. [CrossRef]

32. Nazir, A.; Boom, R.M.; Schroën, K. Influence of the Emulsion Formulation in Premix Emulsification Using Packed Beds. Chem. Eng. Sci. 2014, 116, 547-557. [CrossRef]

33. Nazir, A.; Boom, R.M.; Schroën, K. Droplet break-up mechanism in premix emulsification using packed beds. Chem. Eng. Sci. 2013, 92, 190-197. [CrossRef]

34. Nazir, A.; Maan, A.A.; Sahin, S.; Boom, R.M.; Schroen, K. Foam Preparation at High-Throughput Using a Novel Packed Bed System. Food Bioprod. Process. 2015, 94, 561-564. [CrossRef]

35. Sahin, S.; Sawalha, H.; Schroën, K. High throughput production of double emulsions using packed bed premix emulsification. Food Res. Int. 2014, 66, 78-85. [CrossRef]

36. Eisinaite, V.; Juraite, D.; Schroën, K.; Leskauskaite, D. Preparation of stable food-grade double emulsions with a hybrid premix membrane emulsification system. Food Chem. 2016, 206, 59-66. [CrossRef] [PubMed]

37. Eisinaite, V.; Juraite, D.; Schroën, K.; Leskauskaite, D. Food-grade double emulsions as effective fat replacers in meat systems. J. Food Eng. 2017, 213, 54-59. [CrossRef]

38. Berendsen, R.; Güell, C.; Henry, O.; Ferrando, M. Premix membrane emulsification to produce oil-in-water emulsions stabilized with various interfacial structures of whey protein and carboxymethyl cellulose. Food Hydrocoll. 2014, 38, 1-10. [CrossRef]

39. Trentin, A.; De Lamo, S.; Güell, C.; López, F.; Ferrando, M. Protein-stabilized emulsions containing beta-carotene produced by premix membrane emulsification. J. Food Eng. 2011, 106, 267-274. [CrossRef]

40. Kaade, W.; Güell, C.; Ballon, A.; Mellado-carretero, J.; De Lamo-castellví, S.; Ferrando, M. LWT—Food Science and Technology Dynamic membranes of tunable pore size for lemon oil encapsulation. LWT Food Sci. Technol. 2020, 123, 109090. [CrossRef]

41. Walstra, P. Physical Chemistry of Foods; Marcel Dekker: New York, NY, USA, 2003; ISBN 0824793552.

42. Grace, H.P. Dispersion Phenomena in High Viscosity Immiscible Fluid Systems and Application of Static Mixers As Dispersion Devices in Such Systems. Chem. Eng. Commun. 1982, 14, 225-277. [CrossRef]

43. McClements, D.J. Food Emulsions: Principles, Practices and Techniques; CRC Press: Boca Raton, FL, USA, 2005; ISBN 0849320232.

44. Stang, M.; Schuchmann, H.; Schubert, H. Emulsification in High-Pressure Homogenizers. Eng. Life Sci. 2001, 1, 151. [CrossRef]

45. Schultz, S.; Wagner, G.; Urban, K.; Ulrich, J. High-Pressure Homogenization as a Process for Emulsion Formation. Chem. Eng. Technol. 2004, 27, 361-368. [CrossRef]

46. Van Der Graaf, S.; Schroën, C.G.P.H.; Van Der Sman, R.G.M.; Boom, R.M. Influence of dynamic interfacial tension on droplet formation during membrane emulsification. J. Colloid Interface Sci. 2004, 277. [CrossRef] [PubMed]

47. Walstra, P. Formation of Emulsions. In Encyclopedia of Emulsion Technology. Vol 1. Basic Aspects; Becher, P., Ed.; Marcel Dekker: New York, NY, USA, 1983; pp. 58-127.

48. Lucassen-Reynders, E.H. Dynamic interfacial properties in emulsification. In Encyclopedia of Emulsion Technology. Vol 4; Becher, P., Ed.; Marcel Dekker: New York, NY, USA, 1996; pp. 63-90.

49. Berry, J.D.; Neeson, M.J.; Dagastine, R.R.; Chan, D.Y.C.; Tabor, R.F. Measurement of surface and interfacial tension using pendant drop tensiometry. J. Colloid Interface Sci. 2015, 454, 226-237. [CrossRef] [PubMed]

50. Miller, R.; Fainerman, V.B.; Leser, M.E.; Michel, M. Kinetics of adsorption of proteins and surfactants. Curr. Opin. Colloid Interface Sci. 2004, 9, 350-356. [CrossRef]

51. Miller, R.; Fainerman, V.B.; Makievski, A.V.; Krägel, J.; Grigoriev, D.O.; Kazakov, V.N.; Sinyachenko, O.V. Dynamics of protein and mixed protein/surfactant adsorption layers at the water/fluid interface. Adv. Colloid Interface Sci. 2000, 86, 39-82. [CrossRef]

52. Baret, J.-C. Surfactants in droplet-based microfluidics. Lab Chip 2012, 12, 422-433. [CrossRef]

53. Bremond, N.; Bibette, J. Exploring emulsion science with microfluidics. Soft Matter 2012, 8, 10549. [CrossRef]

54. Garstecki, P.; Fuerstman, M.J.; Stone, H.A.; Whitesides, G.M. Formation of droplets and bubbles in a microfluidic T-junction-scaling and mechanism of break-up. Lab Chip 2006, 6, 437-446. [CrossRef] 
55. Wehking, J.D.; Gabany, M.; Chew, L.; Kumar, R. Effects of viscosity, interfacial tension, and flow geometry on droplet formation in a microfluidic T-junction. Microfluid. Nanofluid. 2014, 16, 441-453. [CrossRef]

56. Steegmans, M.L.J.; Schroën, C.G.P.H.; Boom, R.M. Generalised insights in droplet formation at T-junctions through statistical analysis. Chem. Eng. Sc. 2009, 64, 3042-3050. [CrossRef]

57. Steegmans, M.L.J.; Schroën, K.G.P.H.; Boom, R.M. Characterization of emulsification at flat microchannel y junctions. Langmuir 2009, 25, 3396-3401. [CrossRef] [PubMed]

58. Anna, S.L.; Bontoux, N.; Stone, H.A. Formation of dispersions using "flow focusing" in microchannels. Appl. Phys. Lett. 2003, 82, 364-366. [CrossRef]

59. Sugiura, S.; Nakajima, M.; Iwamoto, S.; Seki, M. Interfacial tension driven monodispersed droplet formation from microfabricated channel array. Langmuir 2001, 17, 5562-5566. [CrossRef]

60. Kobayashi, I.; Vladisavljevi, G.T.; Uemura, K.; Nakajima, M. CFD Analysis of Microchannel Emulsification: Droplet Generation Process and Size Effect of Asymmetric Straight Flow-through Microchannels. Chem. Eng. Sci. 2011, 66, 5556-5565. [CrossRef]

61. Steegmans, M.; Warmerdam, A.; Schroën, K.; Boom, R. Dynamic interfacial tension measurements with microfluidic Y-junctions. Langmuir 2009, 25, 9751-9758. [CrossRef]

62. Wang, K.; Lu, Y.C.; Xu, J.H.; Luo, G.S. Determination of dynamic interfacial tension and its effect on droplet formation in the T-shaped microdispersion process. Langmuir 2009, 25, 2153-2158. [CrossRef]

63. Xu, J.H.; Dong, P.F.; Zhao, H.; Tostado, C.P.; Luo, G.S. The Dynamic Effects of Surfactants on Droplet Formation in Coaxial Microfluidic Devices. Langmuir 2012, 28, 9250-9258. [CrossRef]

64. Wang, X.; Riaud, A.; Wang, K.; Luo, G. Pressure drop-based determination of dynamic interfacial tension of droplet generation process in T-junction microchannel. Microfluid. Nanofluid. 2014, 18, 503-512. [CrossRef]

65. Lan, W.; Wang, Z.; Wang, M.; Liu, D.; Guo, X.; Sun, Q.; Li, X.; Li, S. Determination of transient interfacial tension in a microfluidic device using a Laplace sensor. Chem. Eng. Sci. 2019, 209, 115207. [CrossRef]

66. Brosseau, Q.; Vrignon, J.; Baret, J.-C. Microfluidic Dynamic Interfacial Tensiometry ( $\mu$ DIT). Soft Matter 2014, 10, 3066-3076. [CrossRef]

67. Riechers, B.; Maes, F.; Akoury, E.; Semin, B.; Gruner, P.; Baret, J.C. Surfactant adsorption kinetics in microfluidics. Proc. Natl. Acad. Sci. USA 2016, 113, 11465-11470. [CrossRef] [PubMed]

68. Moiré, M.; Peysson, Y.; Herzhaft, B.; Pannacci, N.; Gallaire, F.; Augello, L.; Dalmazzone, C.; Colin, A. Ultralow Interfacial Tension Measurement through Jetting/Dripping Transition. Langmuir 2017, 33, 2531-2540. [CrossRef] [PubMed]

69. Schroën, K.; de Ruiter, J.; Berton-Carabin, C.C. Microtechnological Tools to Achieve Sustainable Food Processes, Products, and Ingredients. Food Eng. Rev. 2020, 12, 1-20. [CrossRef]

70. Muijlwijk, K. Microfluidic Methods to Study Emulsion Formation. Ph.D. Thesis, Wageningen University, Wageningen, The Netherlands, 2017. [CrossRef]

71. Wang, K.; Zhang, L.; Zhang, W.; Luo, G. Mass-Transfer-Controlled Dynamic Interfacial Tension in Microfluidic Emulsification Processes. Langmuir 2016, 32, 3174-3185. [CrossRef] [PubMed]

72. Steegmans, M.L.J.; de Ruiter, J.; Schroën, C.G.P.H.; Boom, R.M. A Descriptive Force-Balance Model for Droplet formation at microfluidic Y-junctions. AIChE J. 2010, 56, 2641-2649. [CrossRef]

73. Muijlwijk, K.; Hinderink, E.; Ershov, D.; Berton-Carabin, C.; Schroën, K. Interfacial tension measured at high expansion rates and within milliseconds using microfluidics. J. Colloid Interface Sci. 2016, 470, 71-79. [CrossRef]

74. Utada, A.S.; Fernandez-nieves, A.; Stone, H.A.; Weitz, D.A. Dripping to Jetting Transitions in Coflowing Liquid Streams. Phys. Rev. Lett. 2007, 99, 094502. [CrossRef]

75. Engl, W.; Backov, R.; Panizza, P. Controlled production of emulsions and particles by milli- and microfluidic techniques. Curr. Opin. Colloid Interface Sci. 2008, 13, 206-216. [CrossRef]

76. Garstecki, P.; Stone, H.A.; Whitesides, G.M. Mechanism for flow-rate controlled breakup in confined geometries: A route to monodisperse emulsions. Phys. Rev. Lett. 2005, 94, 164501. [CrossRef]

77. Van Der Graaf, S.; Steegmans, M.L.J.; Van Der Sman, R.G.M.; Schroën, C.G.P.H.; Boom, R.M. Droplet formation in a T-shaped microchannel junction: A model system for membrane emulsification. Colloids Surfaces A Physicochem. Eng. Asp. 2005, 266, 106-116. [CrossRef]

78. Van Der Graaf, S.; Nisisako, T.; Schroën, C.G.P.H.; Van Der Sman, R.G.M.; Boom, R.M. Lattice Boltzmann simulations of droplet formation in a T-shaped microchannel. Langmuir 2006, 22, 4144-4152. [CrossRef] [PubMed] 
79. Muijlwijk, K.; Huang, W.; Vuist, J.-E.; Berton-Carabin, C.; Schroen, K. Convective mass transport dominates surfactant adsorption in a microfluidic Y-junction. Soft Matter 2016, 12, 9025-9029. [CrossRef] [PubMed]

80. Muijlwijk, K.; Berton-Carabin, C.C.; Schroën, C.G.P.H. Dynamic Interfacial Tension Measurements during the First Milliseconds of Emulsion Formation. In Abstract Book of The 7th International Symposium on Food Rheology and Structure; ETH: Zurich, Switzerland, 2015; p. 94.

81. Güell, C.; Ferrando, M.; Trentin, A.; Schroën, K. Apparent interfacial tension effects in protein stabilized emulsions prepared with microstructured systems. Membranes 2017, 7, 19. [CrossRef] [PubMed]

82. Schroën, K.; Ferrando, M.; de Lamo-Castellví, S.; Sahin, S.; Güell, C. Linking Findings in Microfluidics to Membrane Emulsification Process Design: The Importance of Wettability and Component Interactions with Interfaces. Membranes 2016, 6, 26. [CrossRef] [PubMed]

83. Krebs, T.; Schroen, C.G.P.H.; Boom, R.M. Coalescence dynamics of surfactant-stabilized emulsions studied with microfluidics. Soft Matter 2012, 8, 10650-10657. [CrossRef]

84. Krebs, T.; Schroën, C.G.P.H.; Boom, R.M. A Microfluidic Method to Study Demulsification Kinetics. Lab Chip 2012, 12, 1060-1070. [CrossRef]

85. Krebs, T.; Schroën, C.G.P.H.; Boom, R.M. Coalescence kinetics of oil-in-water emulsions studied with microfluidics. Fuel 2013, 106, 327-334. [CrossRef]

86. Muijlwijk, K.; Colijn, I.; Harsono, H.; Krebs, T.; Berton-Carabin, C.; Schroën, K. Coalescence of proteinstabilised emulsions studied with microfluidics. Food Hydrocoll. 2017, 70, 96-104. [CrossRef]

87. Schröder, A.; Sprakel, J.; Schroën, K.; Spaen, J.N.; Berton-Carabin, C.C. Coalescence stability of Pickering emulsions produced with lipid particles: A microfluidic study. J. Food Eng. 2018, 234, 63-72. [CrossRef]

88. Hinderink, E.B.A.; Kaade, W.; Sagis, L.; Schroën, K.; Berton-Carabin, C.C. Microfluidic investigation of the coalescence susceptibility of pea protein-stabilised emulsions: Effect of protein oxidation level. Food Hydrocoll. 2020, 102, 105610. [CrossRef]

89. Schroen, K.; Bliznyuk, O.; Muijlwijk, K.; Sahin, S.; Berton-Carabin, C.C.; Schroën, K.; Bliznyuk, O.; Muijlwijk, K.; Sahin, S.; Berton-Carabin, C.C. Microfluidic emulsification devices: From micrometer insights to large-scale food emulsion production. Curr. Opin. Food Sci. 2015, 3, 33-40. [CrossRef]

90. Karbstein, H.; Schubert, H. Developments in the continuous mechanical production of oil-in-water macro-emulsions. Chem. Eng. Process. Process Intensif. 1995, 34, 205-211. [CrossRef]

91. Kolb, G.; Viardot, K.; Wagner, G.; Ulrich, J. Evaluation of a new high-pressure dispersion unit (HPN) for emulsification. Chem. Eng. Technol. 2001, 24, 293-296. [CrossRef]

92. Kobayashi, I.; Takano, T.; Maeda, R.; Wada, Y.; Uemura, K.; Nakajima, M. Straight-through microchannel devices for generating monodisperse emulsion droplets several microns in size. Microfluid. Nanofluid. 2008, 4, 167-177. [CrossRef]

93. Nisisako, T.; Torii, T. Microfluidic large-scale integration on a chip for mass production of monodisperse droplets and particles. Lab Chip Miniat. Chem. Biol. 2008, 8, 287-293. [CrossRef]

94. Muijlwijk, K.; Berton-Carabin, C.; Schroën, K. Cross-Flow Microfluidic Emulsification from a Food Perspective. Trends Food Sci. Technol. 2016, 49. [CrossRef]

95. Amstad, E.; Chemama, M.; Eggersdorfer, M.; Arriaga, L.R.; Brenner, M.; Weitz, D.A. Robust scalable high throughput production of monodisperse drops. Lab Chip 2016, 16, 4163-4172. [CrossRef]

96. Ofner, A.; Moore, D.G.; Rühs, P.A.; Schwendimann, P.; Eggersdorfer, M.; Amstad, E.; Weitz, D.A.; Studart, A.R. High-Throughput Step Emulsification for the Production of Functional Materials Using a Glass Microfluidic Device. Macromol. Chem. Phys. 2017, 218, 1-10. [CrossRef]

97. Van Dijke, K.; Veldhuis, G.; Schroën, K.; Boom, R. Parallelized edge-based droplet generation (EDGE) devices. Lab Chip Miniat. Chem. Biol. 2009, 9, 2824-2830. [CrossRef]

98. Van Dijke, K.C.; Veldhuis, G.; Schroën, C.G.P.H.; Boom, R.M. Simultaneous formation of many droplets in a single microfluidic droplet formation unit. AIChE J. 2010, 56, 833-836. [CrossRef]

99. Van Dijke, K.C.; Schroën, C.G.P.H.; Boom, R.M. Microchannel Emulsification: From Computational Fluid Dynamics to Predictive Analytical Model. Langmuir 2008, 24, 10107-10115. [CrossRef] [PubMed]

100. Van Dijke, K.; Kobayashi, I.; Schroën, K.; Uemura, K.; Nakajima, M.; Boom, R. Effect of viscosities of dispersed and continuous phases in microchannel oil-in-water emulsification. Microfluid. Nanofluid. 2010, 9, 77-85. [CrossRef]

101. Rayner, M.; Tragardh, G.; Tragardh, C.; Dejmek, P. Using the Surface Evolver to model droplet formation processes in membrane emulsification. J. Colloid Interface Sci. 2004, 279, 175-185. [CrossRef] [PubMed] 
102. Sahin, S. Upscaling Microstructured Emulsification Devices. Ph.D. Thesis, Wageningen University, Wageningen, The Netherlands, 2016.

103. Sahin, S.; Schroën, K. Partitioned EDGE devices for high throughput production of monodisperse emulsion droplets with two distinct sizes. Lab Chip 2015, 15, 2486-2495. [CrossRef]

104. Klooster, S.; Sahin, S.; Schroën, K. Monodisperse Droplet Formation by Spontaneous and Interaction Based Mechanisms in Partitioned EDGE Microfluidic Device. Sci. Rep. 2019, 9, 1-12. [CrossRef] [PubMed]

105. Deng, B.; De Ruiter, J. Application of Microfluidics in the Production and analysis of food foams. Foods 2019, 8, 476. [CrossRef]

106. Langevin, D. Influence of interfacial rheology on foam and emulsion properties. Adv. Colloid Interface Sci. 2000, 88, 209-222. [CrossRef]

107. Langevin, D. Bubble Coalescence in Pure Liquids and in Surfactant Solutions. Curr. Opin. Colloid Interface Sci. 2015, 20, 92-97. [CrossRef]

108. Pradines, V.; Krägel, J.; Fainerman, V.B.; Miller, R. Interfacial properties of mixed beta-lactoglobulin-SDS layers at the water/air and water/oil interface. J. Phys. Chem. B 2009, 113, 745-751. [CrossRef]

109. Maldonado-Valderrama, J.; Fainerman, V.B.; Gálvez-Ruiz, J.M.; Antonio, M.-R.; Cabrerizo-Vílchez, M.A.; Miller, R. dilatational rheology of b-casein adsorbed layers at liquid-fluid interfaces. J. Phys. Chem. B 2005, 109, 17608-17616. [CrossRef]

110. Sagis, L.M.C.; Scholten, E. Complex Interfaces in Food: Structure and Mechanical Properties. Trends Food Sci. Technol. 2014, 1-13. [CrossRef]

111. Sagis, L.M.C.; Liu, B.; Li, Y.; Essers, J.; Yang, J.; Moghimikheirabadi, A.; Hinderink, E.; Berton-Carabin, C.; Schroen, K. Dynamic heterogeneity in complex interfaces of soft interface-dominated materials. Sci. Rep. 2019, 9, 2938. [CrossRef] [PubMed]

112. Berton-Carabin, C.C.; Sagis, L.; Schroën, K. Formation, Structure, and Functionality of Interfacial Layers in Food Emulsions. Annu. Rev. Food Sci. Technol. 2018, 9, 551-587. [CrossRef] [PubMed]

113. Dudek, M.; Muijlwijk, K.; Schroën, K.; Øye, G. The effect of dissolved gas on coalescence of oil drops studied with microfluidics. J. Colloid Interface Sci. 2018, 528, 166-173. [CrossRef]

114. Madadlou, A.; Saggiomo, V.; Schro, K.; Fogliano, V. All-aqueous emulsions as miniaturized chemical reactors in the food and bioprocess technology. Curr. Opin. Food Sci. 2020, 165-172. [CrossRef]

115. Hudson, S.D.; Introduction, I. Microfluidic approach for rapid multicomponent interfacial tensiometry. Lab Chip 2006, 6, 427-436. [CrossRef]

116. Martin, J.D.; Marhefka, J.N.; Migler, K.B.; Hudson, S.D. Interfacial rheology through microfluidics. Adv. Mater. 2011, 23, 426-432. [CrossRef]

Publisher's Note: MDPI stays neutral with regard to jurisdictional claims in published maps and institutional affiliations.

(C) 2020 by the authors. Licensee MDPI, Basel, Switzerland. This article is an open access article distributed under the terms and conditions of the Creative Commons Attribution (CC BY) license (http://creativecommons.org/licenses/by/4.0/). 